acid, but with larger amounts of pyridine the end point is more or less indefinite, owing to the acid character of pyridine salts. Even in this case, however, it is possible to get the end point within $0.5 \mathrm{cc}$. of tenth-normal acid, and this does not introduce an error of more than 0.04 gram per liter pyridine.

To check up the method finally, known amounts of pyridine were added to aqua ammonia absolutely free from pyridine. As ordinary chemically pure ammonia always contains pyridine, it was necessary to prepare an aqua ammonia entirely pyridine-free, which was done by heating Merck's c. p. ammonium chloride with calcium hydroxide, neglecting the first portions of ammonia given off, and then absorbing the evolved gas in well-cooled distilled water. The aqua thus prepared contained $24 \% \mathrm{NH}_{3}$, and when carefully neutralized with acid gave absolutely no odor. To this pure ammonia was added weighed amounts of chemically pure pyridine, which had been dried over solid caustic potash and carefully re-fractioned, and the estimation carried through exactly as described above. The following results were obtained, which leave nothing to be desiredin the way of accuracy.

Grams per liter pyridine
present.
0.00
0.05
0.10
0.15
0.20
0.40
0.60
0.80
1.00

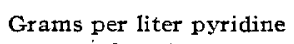

Duplicates of some of the above tests were also run through, but instead of adding methyl orange and titrating the final distillate, it was tested with Nessler solution. In no case, however, was even a slight coloration obtained, showing that the ammonia had been completely destroyed, so that the only alkaline body that passes over in the final distillation is pyridine and its homologues.

Since the above method was worked out, it has been slightly modified by Dr. D. A. Morton, of this laboratory, who found that it was possible to carry out the estimation with only one distillation, with no loss in accuracy. After the aqua is neutralized and the $5 \mathrm{cc}$. of normal caustic added, it is distilled through hypobromite solution. An ordinary one-pint sample bottle is fitted with a two-hole rubber stopper, through one hole of which passes the delivery tube from the distillation flask, reaching nearly to the bottom of the bottle, and through the other a Kjeldahl bulb, connected, of course, by rubber tubing with the flask containing tenthnormal acid to absorb the pyridine. Ioo $\mathrm{cc}$. of sodium hypobromite solution are placed in the bottle, the stopper inserted tightly, and the distillation commenced. The bottle is not cooled, and the steam from the distillation soon heats the contents to boiling, the ammonia coming over being destroyed, and the pyridine passes over to the receiver. With this modification a single test may easily be made in half an hour.

The method described above has been in use in this laboratory for several years, and has proved itself very satisfactory and reliable.

LABORATORY OF THE SOLVAY PROCESS CO. SYRACUSE, N. Y.

\section{FLOUR BLEACHING, ITS RELATION TO BREAD PRODUCTION AND NUTRITION.}

By Johi A. Wesener AND George L. Teller. Received July 29, 1909.

This question has received much attention of late, both in this country and in Europe, in its relation to economics, bread production and nutrition. It has also found a prominent place in the courts, and recent rulings by the Department of Agriculture indicate that it will receive still further attention in this connection. The questions involved are so imperfectly understood, not alone by laymen but also by most scientists, that they should be clearly outlined, and it is the province of this paper to bring this data before the reader in an accurate and concise manner. Not only is the interest of the general public at stake, but there is also involved the rights of the manufacturer, as relating not only to the economics from his view point, but also as these economics may have a direct bearing upon the consumer.

From an early date in the production of wheat flour the bleaching of the color has been practiced by millers before putting their product upon the market. Up to within the last decade the method employed was to store the flour for a period of several months whereby the more or less marked yellow color of the flour was removed.

Not many years ago, a Frenchman, Frichot, ${ }^{1}$ discovered that the gas produced by discharges of electricity through air were capable of whitening the flour. He did not explain properly the cause of this whitening, but attributed it to the production of ozone (which it is now known does not readily bleach flour). ${ }^{2}$ It remained for two Eng- 
lishmen by the name of Andrews $^{3}$ to discover that the bleaching was brought about by the action of certain oxides of nitrogen which are produced when nitric acid is brought in contact with a reducing agent such as ferrous sulphate. Numerous processes have been brought forth for applying this principle to practical bleaching of flour in the mill. The process, which has up to the present time gained the greatest ascendency in this country, is what is known as the Alsop process, where air is pumped through a chamber in which a flaming electric arc is discharging. It can readily be shown that the air discharged from the pump contains small quantities of oxides of nitrogen. In more recent times the use of nitrosyl chloride has been introduced into the art of flour bleaching and possesses advantages over the oxides of nitrogen in the character of the bleach which it produces as well as in the simplicity of application to the flour. This gas can readily be liquefied and bought in small bulk for convenience of transportation and storage. The pressure is ideal for the purpose, being at normal temperature from 15 to 20 pounds to the square inch, and is an important point, as it materially aids in the methods of applying the gas to the flour.

Color is probably one of the most important factors entering into foods, because it plays an important rôle in the mind of the consumer, bringing in a physiological factor which not only affects the palatableness of the food, but also the health of the consumer. The United States government took advantage of thict factor in passing the Oleomargarine Act, imposing a tax of Io cents a pound on this product when colored.

In the earlier milling process where the wheat was ground between stones and the resulting meal separated through a simple bolting device, the flour was often improved by the method of storing which was called ageing, and which ageing process, while maturing the gluten to some extent, was clargely used for the purpose of whitening the flour. By the introduction of the roller process, which became general only within the last half century and only after considerable opposition, a flour was produced which was much whiter in color than was generally produced by the use of millstones. Some consumers of this flour complained that while it was whiter in color it would not make good bread, which was probably due largely to their prejudice against the new flour, commonly known as patent flour. In spite of this prejudice, the desire for the new flour became general and every mill was eventually compelled either to go out of business or adopt this system.

In the rollet process of milling the wheat is first run lightly through a pair of rolls so that it is broken into fragments, and care is taken that the fragments be made as large as possible. The products from the roll are put upon the bolting machine and the coarser portion, including the bran and many larger fragments of the interior of the grain, is bolted off and carried to a second pair of rolls, where the process is repeated. This is again repeated and so the bran finds its way through several pairs of rolls. Each time a considerable quantity of the fragments of the interior portion of the grain are broken off, and by successive bolting and purification the fragments are obtained comparatively free from bran. These fragments are divided into various grades according to their purity, size, etc., and crushed to fragments between various pairs of smooth rolls. The fragments are called middlings. They can be made very pure, and when crushed to flour make an article which is very free from the material which commonly finds its way into the feed. It is to flour produced in this way that the name patent flour is given. Not all of the flour contained in the grain can be obtained in the form of middlings of such character that they can be sufficiently purified to make a better grade of flour. The remaining portion is mixed with fine fragments of bran and often of the germ which is the embryo of the kernel. This portion of the flour is generally named clear grade flour. It is darker in color than the patent flour, and when separated in this way is inferior for bread-making purposes because of the impurities which it contains. When the clear flour and the patent are united in one, they constitute a straight grade flour, which, while superior to the flour made by the old stone mill process, has more nearly its same general character. The improved process of milling has enabled the miller to produce a greater quantity of flour from the wheat as well as flour of a superior quality, for by the old stone method it was impossible to remove all the flour from the bran without also grinding up with the flour an excessively large portion of the bran. From a food and economic standpoint, the clear flour is superior to the patent flour because it contains more of the protein, more of the fat and less of the starch. The same is true of the straight grade flour, for it contains 
the excess of these ingredients found in the clear, and at the same time the objectionable qualities of the clear are largely removed, because the impurities thus more diluted are; except as to color, more beneficial than injurious. The color of the flour which is removed by the bleaching process is distributed throughout the entire flour-producing portion of the wheat grain, but is more abundant in the portion nearest to the bran, which is also the most nutritious. It is the purpose of the modern bleaching process to remove the yellow color instantly. It should be clearly borne in mind, in this connection, that the yellow color which is removed by the bleaching process is entirely independent of any dark or inferior color produced by the presence of the bran which is ground up with the lower grades of flour.

The writers were given the opportunity to examine the first samples of flour bleached by the Andrews process which were brought to this country. A careful comparison of the bleached and unbleached flour was made by us and published in milling journals. ${ }^{4}$ Our examination of these flours was very thorough, and although we set about the analysis with somewhat prejudiced minds, we were unable to find any objections whatever to the sample of bleached flour, or any material differences between the two flours except that which was apparent in the color. Our findings with regard to this matter were put before the millers by one of the writers at the Operative Millers Convention, at St. Louis, and by the other at the meeting of the Federation of Millers at Buffalo. Shortly after this time and since, other investigators have made a careful study of the subject of bleaching flour and all, with the exception of two, have arrived at substantially the same conclusions that we gave in our first article and public lectures. Those prominent in these investigations are Fleurent, ${ }^{5}$ of France, Prof. Harry Snyder, ${ }^{\beta}$ of the Minnesota Agricultural Experiment Station, Prof. Ladd and Mr. Stallings, ${ }^{7}$ of North Dakota, Dr. Avery ${ }^{8}$ and later Prof. Alway, ${ }^{9}$ both of the University of Nebraska, and lately Dr. Ludwig Weil, ${ }^{10}$ Strassburg, Germany.

It has already been stated that the active agents in the bleaching of flour are nitrogen oxides and nitrosyl chlorid. Both of these substances result in decomposition products which give the usual test for nitrites. The test which is commonly used for detecting small quantities of this substance is known as the Griess-Ilosvay test, which is among the most delicate tests for any substance which is known to chemists. So delicate is this test that, according to Warrington, it is capable of detecting one part of nitrous anhydride in a billion parts of water. It was because of this very delicate test that it was possible to discover the residues of these gases in the flour.

The chemistry involved in the bleaching of flour has received much attention by us. We have isolated the coloring matter and have identified it or at least have established a very close relationship for it with other natural vegetable colors. It is not the province of this article to go into this phase of the question. The chemistry of this reaction will be taken up by us in a later article. The coloring matter of flour is the one material which shows the great avidity for uniting with the gases which are used in bleaching. The action on the coloring matter is instantaneous, and the amount required for the purpose of bleaching the flour is very minute. If an excess of the gas is used, it will eventually combine with other substances, primarily the gluten and finally the oil. It is only when the flour is overbleached and ruined that the action on these constituents of the flour is sufficient for it to be detected either by chemical or by physical properties. ${ }^{11}$ It was conceded in the flour bleaching case conducted in North Dakota, as well as at the hearing in Washington, D. C., that the average amount of nitrite-reacting nitrogen in commercially bleached flours is practically one part per million. In our own experiments we have often found much less than this amount. It has been still further conceded ${ }^{12}$ on the part of even those opposed to the bleaching of flour that only a small proportion, and in some instances not any, of the nitrite-reacting nitrogen is present in the bread. We have found this disappearance of nitrite-reacting nitrogen to be due in a large measure to the action of the yeast which is used in the bread.

The nitrite-reacting material of flours is also removed by the action of heat. This may be clearly shown by the tables given below. Quantities of spring patent flour were dried over night, and in the morning examination for nitrites was made in the usual way.

$$
\begin{aligned}
& \text { Temperature of oven. } \\
& 105^{\circ} \mathrm{C} . \\
& 75^{\circ} \mathrm{C} . \\
& 40^{\circ} \mathrm{C} . \\
& \text { Not dried }
\end{aligned}
$$

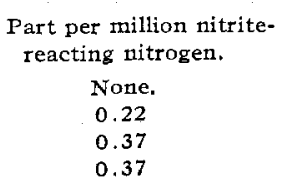


Four lots of spring patent flour or 20 grams each were made into a sponge dough and put in the proving case over night. In the morning it was found the temperature had risen somewhat above $100^{\circ} \mathrm{F}$. The flours were tested in the morning for nitrites in the usual way.

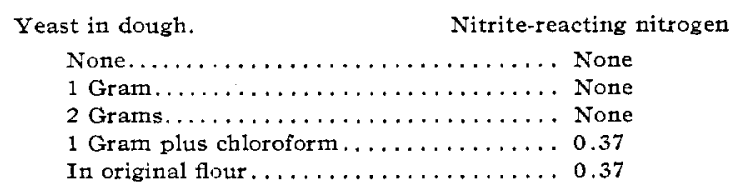

Four lots of spring patent flour of 20 grams each were made into dough as on the preceding day and allowed to stand over night at room temperature. Determinations of nitrites were made in the morning.

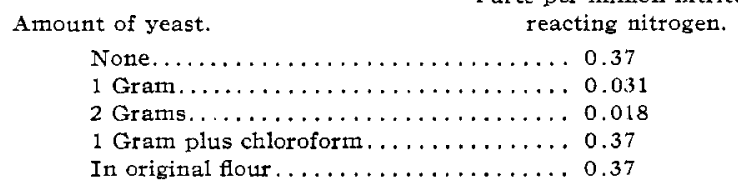

It will be noted that in the first experiment where the flour is dried over night at a temperature of $105^{\circ} \mathrm{C}$. that all of the nitrite-reacting nitrogen disappears. At a temperature of $75^{\circ} \mathrm{C}$. it is reduced from 0.37 to 0.22 . At a temperature of $40^{\circ} \mathrm{C}$. no change takes place. In experiment No. 2 it will be noticed that from flour made into a dough with water and allowed to ferment in a proving case all of the nitrite-reacting nitrogen disappears. The same is true when I gram and 2 grams of yeast are added to the flour before making a sponge. When, however, chloroform was added to stop the action of yeast and bacteria, the nitrites remained as in the original flour. In the third experiment we notice that this change does not take place in the sponge made directly from flour without the addition of yeast when kept at ordinary room temperature. Better action takes place, however, when one and two grams of yeast are added to the flour. There is a reduction then from 0.37 to 0.018 . In the third experiment the nitrite-reacting nitrogen would have all disappeared had the correct incubating temperature been used, except when chloroform was added. From the results of this experiment we see that drying at sufficiently high temperature dispels all of the nitrite-reacting nitrogen and that living bacteria and yeast consume it:

That the presence of even considerable amounts of nitrite-reaction nitrogen in flour acts favorably to the development of yeast in dough and not as a preservative is apparent from the following:

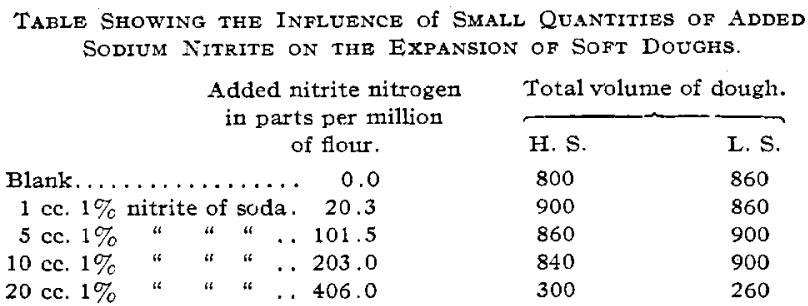

In making the above expansions Ioo grams of Pillsbury's best flour were used in each dough in connection with the following other ingredients: water, 75 grams; yeast, Io grams; sugar, 3 grams. Total dough, I88. In those doughs in which the solution of nitrite was used it was made to take the place of the other water used so that all the doughs contained the same amount of liquid. Expansions marked L. S. were at slightly higher temperature than those marked $\mathrm{H}$. S., the temperature of the two lots being about L. S. $95^{\circ} \mathrm{F}$. and $\mathrm{H}$. S. $90^{\circ} \mathrm{F}$.

It will be seen from the above that no effect injurious to the expansion of the dough is apparent when a quantity of nitrite-reacting nitrogen is added to the flour in quantities 200 times as great as is present in commercially bleached flour. On the other hand, we find this larger amount to be beneficial to such expansion. It was also found that when bleaching gases are added to the flour sufficient to produce nitrite-reacting nitrogen to the extent of 60 parts per million, the flour was entirely destroyed for commercial purposes because of the well-known xanthoproteic reaction whereby the flour was highly discolored, producing a reddish yellow shade, and because the character of the gluten was changed by the action of this large amount of the acid-producing gases upon the gluten. Even in this aggravated condition the growth of the yeast was not prevented and the bread-making property of the flour was not destroyed, although the bread was of inferior quality. Attention should be called to the fact that in the experiment noted above sodium nitrite was used, while in the gas-treated four the sodium was not added, the acid in this case being in part at least united with the gluten, forming with it the well-known class of syntonin bodies. It is known ${ }^{13}$ that bodies of this character are continually formed during the process of bread-making by yeast, and are an essential step in such process of bread-making. 
One of the contentions of those who are opposed to the bleaching of flour is that it leaves a deleterious substance in the nature of a preservative in the flour. The experiment cited above in which we have shown that the bacteria and yeast consume the nitrite-reacting material of the flour is sufficient answer to this contention

We have been making daily examinations of flour received from all parts of the United States and from foreign countries, including Canada, England and South America. This has naturally brought us in contact with flours of all kinds, from all classes of wheat, and representing all methods of milling. This work has been done for the purpose of ascertaining the bread-making and commercial value of these flours. During the last five years probably 90 per cent. of the flours which we have received have been bleached, and we have not in a single instance found any flour which appeared to be in any way injured by the process of bleaching. The analyses which we make of these flours are very thorough, as the commercial value, which depends on the quality of the bread, is based on our reports. In addition to this general analytical work on flours, we have made a thorough and exhaustive study of many flours, bleached and unbleached, to determine any effects which might have been produced by the action of bleaching gases upon the bread-making qualities of the flour. We have found that in every instance the only essential change in the character of the flour was in a whitening of the color and in some instances an increase of the water-absorbing capacity of the flour. Where there has been any slight difference in the volume of the bread, which could not be attributed to natural variation in the work, it has been, if anything, slightly in favor of the bleached flour. The same is true of the number of loaves of bread which are produced from a barrel of flour. The amount of yeast necessary for the production of bread from bleached flour, which we always call the fermenting period, was in no way increased over that required for the unbleached flour. The quality of the gluten, as shown by its capacity for expanding into a good-sized loaf of bread, has not been found to be in any manner injured. The average value, which in our report is based upon the color of the flour, the character of the bread, the amount of bread and the size of the loaf, was a little higher for the bleached flour than for the unbleached, because the color of the flour and the color and quality of the bread. were improved.
The flavor of bread is subject to much variation, due to the methods of bread-making, and is also one of the most difficult points to determine in the comparison of breads under examination. We have made careful comparisons along this line and have been unable to detect any deterioration of flavor when both flours, bleached and unbleached, were submitted to the same process of bread-making. We have already called attention to the fact that the patent flour, as compared with the clear, is relatively deficient in protein, fat and mineral matter, and for this reason possesses less nutritive value than the clear flour. We have also pointed out that when these two flours are combined they constitute the straight grade flour which is intermediate in character between the patent and the clear. While an experienced eye can readily distinguish between the grades of flour used when a straight grade flour from which the color has been removed is baked into bread and compared with bread from a patent flour from which the color has not been removed, it is our experience that preference will be given to bread made from the straight grade flour.

Typical ANalysis of Bleached aNd LNBleached FIoUR.

\begin{tabular}{|c|c|c|c|c|c|c|}
\hline & 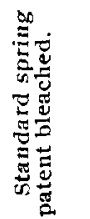 & 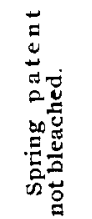 & 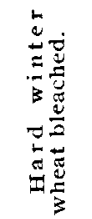 & 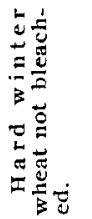 & 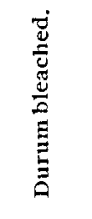 & 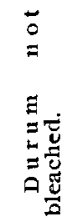 \\
\hline Gluten, per cent... & 11.0 & 11.0 & 11.5 & 11.5 & 10.5 & 10.5 \\
\hline Ash, per cent..... & 0.42 & 0.42 & 0.40 & 0.40 & 0.60 & 0.60 \\
\hline Absorption, per cent. & t. 61.0 & 61.0 & 62.0 & 62.0 & 61.0 & 61.0 \\
\hline Color........... & 100.0 & 99.0 & 100.5 & 99.0 & 97.5 & 95.0 \\
\hline Loaves, per bbl.... & 100.0 & 100.0 & 100.6 & 100.6 & 100.0 & 100.0 \\
\hline Size of loaf. . ..... & 100.0 & 100.0 & 100.0 & 100.0 & 98.0 & 98.0 \\
\hline Quality of loaf.... & 100.0 & 99.7 & 100.3 & 99.7 & 99.0 & 98.0 \\
\hline Average value.... & 100.0 & 99.7 & 100.4 & 99.8 & 98.6 & 97.7 \\
\hline Fermenting petiod & 100.0 & 100.0 & 102.2 & 102.2 & 97.7 & 97.7 \\
\hline Quality of gluten. & 100.0 & 100.0 & 97.8 & 97.8 & 102.4 & 102.4 \\
\hline
\end{tabular}

NUTRITIONAL EXPERIMENTS.

Twenty-four white rats were purchased of a rat dealer in Chicago during the month of July, 1908 , the lot including ro females and it males. These were put in several cages, weighed after dividing, and arranged on shelves in a cool, well-ventilated room, where all were given similar treatment as to food, water and ventilation. Boxes suitable for their protection and comfort were put in each cage. On the 28 th of July the rats were arranged so that each of two cages should contain seven males, and each of two others should contain five females. An effort was made to have the weight of males in the two cages about equal and also the 
weights of females of the two cages about equal. The experiment in feeding was begun on the 28 th of July. Within two or three days one of the rats died from causes common to rats and in no way connected with the experiment. The weights of the rats at the beginning and end of the experiment are shown in the table given below:

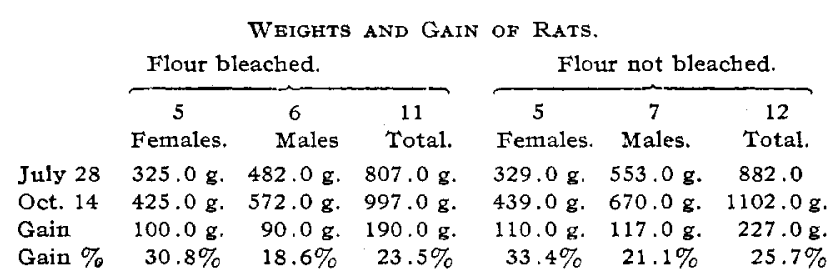

Figures show weight in grams and also gain in per cent. of the original weight.

A barrel of flour was procured from the BergerCrittenden Milling Company, of Milwaukee, which was known at that time to have no bleacher, and which was fully borne out by tests to be entirely unbleached. Soon after receiving at the laboratories, the flour was put into four 50-pound tight tin flour bins for preservation. The flour from one of these bins was passed through the gases of the Alsop bleaching machine in a manner identical with that used in the flour mills. The time required for the passing of the flour through the gases produced from a generator suitable for a roo-barrel mill was two minutes. Tests were made for the amount of nitrite in the flour bleached in this manner, and the nitrite-reacting nitrcgen was found to be three-tenths parts in a million. The flour was again run through the bleaching machine in the same manner as at first and the nitrites again determined. The amount found after this second bleaching was 0.56 part per million of nitritereacting nitrogen. On the following day biscuit was made from the bleached and unbleached flour. No nitrites whatever were found in either the flour or the biscuit unbleached. In the biscuit from the bleached flour the amount of nitrites found was equivalent to 0.3 part per million of nitrite-reacting nitrogen. It was considered that the bleaching of this flour had not been sufficient to meet the objections which might be raised as to its having been given sufficient treatment, and it was put through the bleacher twice more in the same manner as already described. After this last bleaching the nitrite determination was again made upon the flour on July $3 \mathrm{I}$, and was found to be, on the flour four times bleached by the Alsop machine, equivalent to 0.79 part of nitrite-reacting nitrogen per million. The flour was now put aside in the laboratory for use in the making of bread and biscuit for the experiment. The composition of these flours before and after bleaching was determined in the usual manner in which we determine the characteristics of different flours in making our commercial laboratory reports, and the results are given herewith:

\begin{tabular}{|c|c|c|c|}
\hline & $\begin{array}{l}\text { Spring } \\
\text { patent. }\end{array}$ & 6796 & $\begin{array}{c}6796 \\
\text { bleached }\end{array}$ \\
\hline Gluten, per cent............. & 10.5 & 11.0 & 10.9 \\
\hline Ash, per cent. $\ldots \ldots \ldots \ldots \ldots \ldots \ldots$ & 0.42 & 0.49 & 0.49 \\
\hline Absorption, per cent.............. & 62.0 & 62.0 & 62.0 \\
\hline Color $\ldots \ldots \ldots \ldots \ldots \ldots \ldots$ & 100.0 & 99.0 & 99.5 \\
\hline Loaves, per barrel. . . . . . . . . . . & 100.0 & 100.0 & 100.0 \\
\hline 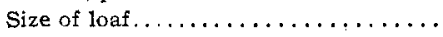 & 100.0 & 100.0 & 100.0 \\
\hline 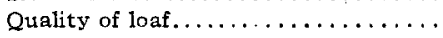 & 100.0 & 98.7 & 99.0 \\
\hline Average value.$\ldots \ldots \ldots \ldots \ldots \ldots$ & 100.0 & 99.4 & 99.6 \\
\hline Fermenting period............. & 100.0 & 102.5 & 102.0 \\
\hline 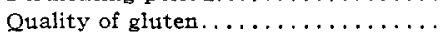 & 100.0 & 97.5 & 98.0 \\
\hline Moisture.................. & $\ldots$ & 12.85 & 12.0 \\
\hline Acidity, as lactic acid............ & $\cdots$ & $0.117 \%$ & $0.117 \%$ \\
\hline
\end{tabular}

The bread used in these experiments was made substantially as follows: 500 grams of each flour were mixed with 3 IO $\mathrm{cc}$. of water, 12 grams of compressed yeast, I5 grams of sugar, 7.5 grams of salt and 15 grams of lard. The dough was allowed to develop for two hours with one working, which working was done at the end of the first hour. At the end of the two hours the dough was molded into a loaf and put in the pan, where it was allowed to prove until it was ready for baking in the oven. It was baked usually in the electric oven until sufficiently done, requiring about 45 minutes. It was then taken out of the oven, cooled, and subsequently put in suitable tin boxes to preserve for the experiments. A portion of the time biscuits were substituted for the bread, so that the rats might have some variety of diet, and so that the teeth of the rats might be kept in somewhat better condition by their gnawing the harder biscuit. The biscuits were made substantially as follows:

Two hundred and fifty grams of each flour, II5 grams of water, 2 grams of salt, and 5 grams of Dr. Price's cream baking powder were mixed together, rolled to suitable thickness, cut with a tin biscuit cutter, put in a pan and baked in the electric oven. The amount of nitrites remaining in the bread and biscuit was determined on many of the samples, and the average amount found was 0.03 part per million of nitrite-reacting nitrogen for the bread and 0.24 part for the biscuit from the bleached flour. The average amount of nitritereacting nitrogen in the bread from the unbleached flour was none and in the biscuit from the un- 
bleached flour was 0.02 part per million. The bread in these experiments was purposely made by an unusually short process, which would tend to leave in it much more nitrite-reacting nitrogen than would remain when the bread is given the usual amount of fermentation. Even in this short process of bread-making the nitrites were in many instances entirely removed. The rats were fed right and morning of each day and were supplied with sufficient water in a suitable tin vessel placed in their cage. The amount of bread or biscuit given at each feeding was equivalent to about 5 per cent. of the weight of the rats daily. This amounted to about 50 grams for the rats fed bleached flour and a trifle more for the rats fed unbleached flour.

The supply of bleached flour used in feeding these rats was exhausted about the 3 rd of October, and another quantity of the same flour was run through the bleaching apparatus three times, in the same manner as on the previous occasion. The amount of nitrite-reacting nitrogen in the flour thus bleached was $I .56$ parts per million, which was much in excess of what would possibly be introduced into the flour by a single bleaching. The rats were fed on bread and biscuit from this flour for about one week. The amount of nitrite-reacting nitrogen in the biscuit from this flour was 0.6 part per million and from the bread was 0.3 part per million.

At the end of the feeding period a considerable number of the rats were dissected by the Biological Division of the Columbus Laboratories under the direction of Dr. Adolph Gehrmann, and the data obtained in this manner is given below:

Notes on individual rats as dissected: The rats were killed with chloroform, stretched in a proper manner, and opened by a ventral incision extending the entire length of the body. Examinations were made on the following points, and where normal no mention is made of them in the following notes:

Nutrition and blood supply of intestines; general condition of intestines, stomach, liver, kidneys, spleen, heart, lungs, and also of amount of fat in mesentery and omentum. Portions of organs, as follows, were removed and put into a seven per cent. solution of formaldehyde for subsequent examination under microscope: Anterior portion of right lobe of liver; one-half of left kidney; middle portion of stomach including portions of the cardiac and pyloric ends; one-half of spleen and such other special portions as occasion required. The re- maining portions of each rat were also preserved in formaldehyde for any future examinations which might be desired.

NOTES ON SERIES FED BLEACHED FLOUR.

Cages $I$ and 2.

Rat No. I. Stomach partially distended with food.

Rat No. 4. Tapeworm in intestines.

Rat No. 7. White nodule of fat within capsule of left kidney. $\mathbf{I} / 2$ right kidney taken for microscopic examination.

Rat No. II. Nothing abnormal found.

Rat No. r3. Much congestion of abdominal vessels. Stomach distended with gas; small ulcer on interior wall. Tapeworm in intestines; hydatid cyst in liver. Hardly any fat in mesentery. This was the most unthrifty rat in the experiment.

Rat No. 16. Intestines somewhat congested; hardly any fat in the mesenteries.

Rat No. 23. One of the most thrifty-looking rats in the entire experiment. No defects of any kind whatever found.

\section{SERIES FED FLOUR NOT BLEACHED. \\ Cages 3 and 4 .}

Rat No. 2. Stomach fairly well distended with food. Examination showed nothing abnormal.

Rat No. 5. Tapeworms in small intestines. Spleen appeared somewhat small.

Rat No. 8. Normal appearance throughout.

Rat No. ro. Apparently abnormal contraction between cardiac and pyloric ends of stomach causing hour-glass shaped organ.

Rat No. I4. Some congestion of abdominal blood vessels. Small intestines contained three very large tapeworms. Stomach somewhat distended with gas. Darkened spots on anterior portion of anterior lobe of liver. Spleen presented irregular mottled appearance. Slight consolidation in upper lobe of left lung.

Rat No. I7. Small tapeworm in small intestine.

Rat No. 18. Some gas in intestines. Some tendency toward diarrhea. Small infiltration of fat into capsule of left kidney.

Rat No. I9. Slight congestion of small intestines. One very large tapeworm in small intestines.

IRREGULARITIES FOUND CLASSIFIED AS TO ORGANS EXAMINED.

Nutrition and Blood Supply of Intestines.--Some congestion of abdominal blood vessels found in 
rat No. I4, unbleached series, and much in rat No. I3 of bleached series.

Abnormal Condition of Intestines.-Tapeworms found in rats Nos. 4 and 13 of bleached flour series; in Nos. $5,14,17$ and 19 of unbleached series. Some inflammation in rats Nos. 13 and 16 of bleached series; also in rats Nos. I4 and I9 of unbleached series. Tendency to fermentation and diarrhea were noticeable in rat No. I 8 of unbleached series.

Stomach.-Stomachs were more or less distended with gas in rats No. I3, of bleached series, and No. I4, of unbleached series. Rat No, Io of the unbleached series showed marked hour-glass contraction between cardiac and pyloric ends.

Liver.-Hydatic cysts were found in rat No. 13 of bleached series. Darkened spots were found on the anterior portion of the anterior lobe of No. I 4 of the unbleached series.

Spleen.-That of No. 5 of unbleached series was unusually small and that of No. I4 of the same series presented an irregular mottled appearance.

Kidneys and Renals. - Whitish nodules of fat were found within the capsules of one of the kidneys of No. I8, of unbleached series, and No. 7 , of bleached series.

Heart.-No abnormalities were apparent.

Lungs.-Slight areas of consolidation in upper lobe of left lung of No. I 4 of unbleached flour series.

Fat in Mesenteries and Omentum.-Deficient in mesenteries of No. I 3 of bleached flour series, and in No. I6 of same series. Also in No. I4 of unbleached series.

\begin{tabular}{cccc} 
& \multicolumn{3}{c}{ Series Fed on Flour Not BLeached. } \\
No. of tat. & Sex. & Weight in grams. General appearance. \\
2 & Male & 132 & thrifty \\
5 & Female & 82 & fairly thrifty \\
8 & Male & 92 & fairly thrifty \\
10 & Male & 83 & not thrifty \\
14 & Male & 71 & not thrifty \\
17 & Male & 79 & not thrifty \\
18 & Female & 84 & fairly thrifty \\
19 & Female & 76 & fairly thrifty
\end{tabular}

The remaining rats of this series were thrifty in appearance except one female which did not appear thrifty.

\begin{tabular}{cccc}
\multicolumn{4}{c}{ Series FEd ON Bleached Flour. } \\
No. of tat. & Sex. & Weight in grams. General appearance. \\
1 & Male & 110 & thrifty \\
4 & Female & 110 & thrifty \\
7 & Male & 120 & fair \\
11 & Female & 83 & not thrifty \\
13 & Male & 47 & not thrifty \\
16 & Male & 74 & not thrifty \\
23 & Female & 129 & very thrifty
\end{tabular}

The unkilled rats of this series were of thrifty appearance.
A series of feeding experiments was conducted with rats covering a period of several months. The bread which they received was made from flour which had been bleached with nitrosyl chlorid gas. The general findings were substantially the same as in the experiment detailed above. There were noticed no nutritional disturbances of any kind, and the post-mortem examination showed no lesions which in any way could be attributed to the bread made from this flour. In addition to the feeding experiments conducted with the rats, we have fed the guinea pigs, which we have always on hand for experimental purposes, bread from bleached flour covering a period of more than six years. During this time we have never once noticed any symptom or sign in the health of the animals which could in any way be traced to the bread made from bleached flour. Post-mortem examinations never revealed any lesion which could in any way be associated with the food which they had been receiving.

Ladd $^{14}$ has given results of experiments where alcoholic extracts of bleached and unbleached flours were evaporated under specified conditions and the residue administered to rabbits. The extracts from the bleached flour were reported by him to have produced death in a short time, the post-mortem findings being those of a corrosive poison. These experiments have been carefully repeated by Prof. Haines and Prof. Snyder, ${ }^{12}$ who were not able to obtain results showing any indication of poison in the rabbits.

In working in conjunction with Prof. Haines at the Columbus Laboratories in November, I908, several lots of flour were taken for extraction with 90 per cent. alcohol following the same general lines of investigation as laid down by Iradd. The flours used in these experiments were Sunnyside, marked 6796 unbleached, the same bleached by passing through Alsop gases four times, and the same bleached by very excessive treatment with nitrosyl chlorid. The flour bleached by the Alsop process contained 2.8 parts of nitrite-reacting nitrogen per million; that excessively bleached by the nitrosyl chlorid was entirely destroyed for commercial purposes and contained 30 parts nitritereacting nitrogen per million. Of the three samples of 6796 each flour in lots of 750 grams each was put in each of two bottles and $1750 \mathrm{cc}$. alcohol added to each bottle, making a total of 1500 grams of each flour and 3500 grams of alcohol for each. These were agitated thoroughly during the after- 
noon of the day, were allowed to settle over night, and the clear supernatant fluid was poured from each on the following morning. This liquid was filtered to remove any starch which might be carried over. The total amount of liquid obtained for the flour treated with nitrosyl chlorid was I280 cc.; that for the flour treated by the Alsop process I 2 Io cc.; that for the flour not bleached was substantially the same. Each of these liquids was introduced into a heavy glass globe of about I $500 \mathrm{cc}$. capacity. Those having the larger amounts were divided in two portions and a part of the liquid evaporated off before the remainder was atded. The globes were connected with Liebig condensers at the lower end of which was an Erlenmeyer flask with a wide neck and side tube such as is used for vacuum filters. The whole was then connected with the small vacuum pan in the laboratories. Two of the glass globes were put in a large dishpan filled with water and so arranged that heat could be applied. Two others were put in another pan in a similar manner. The evaporation was then done by the assistance of the heated water and the vacuum pan. The time required for the evaporation was six hours. The maximum temperature of the liquid in the several flasks was $48^{\circ} \mathrm{C}$. The average vacuum as shown by the manometer connected with the vacuum pan was from 23.5 to 25.5 inches. The removal of the alcohol in this manner was quite complete, but to still further remove small quantities which were in the flask, each flask was closed with a pledget of cotton and placed in the incubator heated by one 16-candle power electric light so that the temperature was about $37^{\circ} \mathrm{C}$. and allowed to remain at this temperature over night. In the morning there was no odor of alcohol in any of the flasks. The residue in the several flasks was of an oily consistency with some sediment which was not entirely soluble in the clear oil. The oil was carefully poured from the flasks containing the Alsop process bleach and the nitrosyl chlorid bleach on the samples of Sunnyside flour, and allowed to drain into beakers until no more oil would flow from the flasks. These two flasks were carefully broken and the material remaining in them scraped from the glass. The weight of the total residue obtained from the flask treated with nitrosyl chlorid was 8.9 grams, and that from the flask of which the flour was treated with the Alsop process was 6.746 grams. 3.266 grams of that taken from the nitrosyl chlorid flour were weighed and mixed with water and $2 \mathrm{cc}$. of $95 \%$ alcohol so that the total volume of the mixture was about Io cc. This amount of fat corresponded to nearly $25^{\circ}$ grams of flour. It was taken up by means of a small glass syringe and fed to a rabbit weighing 2 I 30 grams. No ill effects were apparent in the rabbit. It went to eating vigorously in the course of 15 minutes and showed no symptoms of distress of any kind. The oil from the Alsop process bleached flour was divided into two portions as nearly equal as possible. The first of these was treated in the manner described above and given to a rabbit, but unfortunately the soft catheter at the end of the syringe was introduced into the trachea which led to disturbance in the breathing of the rabbit, so that it was considered advisable to kill it shortly after and find the cause of the distress. This was done, and a post-mortem examination showed the lungs to contain much foreign matter and naturally highly congested. The other organs were found to be perfectly normal. The remaining portion of the Alsop process flour extract was fed to another rabbit in the same manner as that fed from the nitrosyl chlorid bleached flour, and no indications of distress whatever were occasioned by this flour. The weight of the rabbit which was fed was substantially that of the other, $2100 \mathrm{~g}$. Both rabbits were kept under observation for a considerable time and no indication of distress or unusual symptoms were apparent. The acidity of the alcohol extract was identical for the three samples of Sunnyside flour, the unbleached, that bleached by the Alsop process, and that strongly overbleached by nitrosyl chlorid.

In the flour bleaching trial ${ }^{15}$ in England, Wilcox and Luff, working independently, repeated experiments with rabbits as outlined by Ladd using unbleached, commercially bleached and strongly commercially bleached flour, making all told more than 50 experiments and report that in these experiments they were in no instance able to kill the rabbits because of any poisonous substance in the extracts, or to produce any toxic symptoms other than such as might come from the alcohol which was administered in connection with the extract. Judge Pollock, of North Dakota, and Judge Warrington, of England, both having listened to the testimony detailed by Ladd and the other experimenters, as mentioned above, sum up in their decision that bleached flour does not contain a deleterious substance. 
If we calculate that the total amount of nitrous and nitric acid which might be present in one of the flours which was used by Ladd ${ }^{14}$ for his test, based upon double the amount of nitrite-reacting nitrogen found ( 3 parts per million) and all calculated to nitric acid, it would be equivalent to only 5.4 milligrams ( $\mathrm{I} / \mathrm{\text {IO}}$ drop) of nitric acid. This amount of nitric acid is practically I/ Ioo the medicinal dose of nitric acid as given in the U. S. Dispensatory, and according to Ladd's testimony the liquid administered to the rabbits was much greater in amount than necessary to produce the dilution specified in that work for internal doses of nitric acid. Under the circumstances we could not expect any corrosive action from this amount of acid, even assuming that it could have been separated out of the flour as free acid without in any manner combining with the organic matter of the flour and alcohol.

It has been asserted by Prof. Ladd and others testifying against the bleaching of flour that proof of the action of the bleaching gases upon the oil of commercially bleached flours was apparent from the altered iodin absorption of the oil. Careful work upon this point had been done by the United States Department of Agriculture, and the results of the work submitted as testimony in the North Dakota flour bleaching trial ${ }^{14}$ in which it was shown that in nine cases out of ten in which the "unbleached" samp.e did not show the presence of nitrites the difference between the iodine absorption of the fat of the bleached and unbleached flours was within the limit of experimental error, and this, notwithstanding the limit of experimental error on this test for iodine absorption, was considered to be not greater than the very close figure of one-half of one per cent. The readiness with which oil of wheat takes up oxygen of the air in its preparation for analysis is a potent factor in altering the iodine absorption of the oil.

The same table of analysis also gives detailed results of a considerable number of the determinations of the acidity of the bleached and unbleached flours in which the difference between the considerable number of samples examined was again within the limit of experimental error. We ourselves have never found such increased acidity in our own experiments with commercially bleached flours. Even assuming it to exist to a slight extent, it would not act injuriously on the breadmaking quality of the flour, for as already stated, the changes brought about by the action of acids produced during fermentation are among the constant and necessary steps in the preparation of dough for baking.

As throwing some light on the influence of the bleaching gases upon the digestive action of pepsin on the proteids of flour, we will give the results of the following digestion experiments: In each case ro grams of flour were used, one unbleached, the other bleached, showing 2.8 parts of nitritereacting nitrogen per million. Each was treated with $50 \mathrm{cc}$. of the official pepsin and hydrochloric acid mixture and kept at animal temperature for one hour with occasional agitation. Then both were made up to $250 \mathrm{cc}$. with cold water and $50 \mathrm{cc}$. were filtered from each. These were examined by the Kjeldahl method in duplicate and the unbleached gave $0.0369 \mathrm{~g}$. nitrogen, the bleached $0.038 \mathrm{~g}$. in one set, and in the other set $0.036 \mathrm{I} \mathrm{g}$. for unbleached, and $0.0375 \mathrm{~g}$. for the bleached. We thus see that the peptonizing action of this enzyme was in no way retarded because of the presence of the nitrites.

Diazo Test.--roo grams of unbleached flour were introduced into a flask of about one liter capacity, and carbon dioxide passed into it for I I/4 hours with frequent vigorous agitation. Dilute hydrochloric acid which had been recently boiled was added warm and the mixture agitated. The evolved gas was then swept by a stream of carbon dioxide into a Schiff azotometer containing the usual solution of caustic soda. A small amount of gas passed to the top which could not be absorbed by repeated agitation. The volume of this gas was I.4 cc. It was tested with a lighted paper. It did not burn nor did it support combustion when tested as indicated by Prof. Ladd. ${ }^{14}$ The above experiment, carried on in coöperation with Prof. Haines, was carried out as detailed by Ladd ${ }^{14}$ and used by him as testimony in North Dakota to show the presence of diazo compounds of the nature of tyrotoxicon resulting in bleached flour from the action of the bleaching gases upon the constituents of the same. The amount of gas which he obtained from the bleached flour is substantially the same as we obtained in the above experiment from unbleached flour, and is undoubtedly air which adheres to the particles of flour and which cannot be removed even by the most careful and persistent treatment with carbon dioxide. That the experiments tend to show the presence of tyrotoxicon, or that such tyrotoxicon would be formed by the action of bleaching gases 
on flour is not probable when we remember that this material, as found in cheese and other milk products, is wholly the result of bacterial growth, and that it is of an exceedingly unstable nature.

Nitrites and nitrite-reacting substances, which form the chief basis of the contentions of the opponents of bleached flour against that material, are very widely distributed throughout the mineral, vegetable and animal kingdoms. We have entered more into detail in the question of this distribution in a former paper, ${ }^{16}$ and will summarize the facts only very briefly here. Nitrites are found in many drinking waters. They are objected to in that connection because their presence is an indication of the bacteriological or sanitary condition of the water, and not because of poisonous qualities of the nitrites themselves. Nitrites are found in considerable quantities in soils and in such common foodstuff as salt, baking soda, and baking powder. They have been found in small quantities in green vegetables including celery and other articles of food. They have been found in considerable quantities in preserved meats, especially those in the preparation of which saltpetre is used and the formation of nitrites is apparently an essential step in the preservation of meats by saltpetre. We have found in ham bought in the open market as high as five parts per million of nitrite-reacting nitrogen, or five times the average maximum amount found in commercially bleached flour. Nitrite-reacting nitrogen is found in all parts of the animal body, and is nearly always present in comparatively large quantities in the human saliva, including the normal saliva of healthy nursing infants. We have found in the saliva of man as high as I 3 parts per million of nitritereacting nitrogen, which is 13 times that found in bleached flour. While nitrite-reacting nitrogen can nearly always be found in flours which have been bleached with oxides of nitrogen, the presence of nitrites in flour is not a proof that they have been bleached, as shown by Weil ${ }^{10}$ who has obtained reaction for this substance by the GriessIlosvay test in samples of unbleached flour and in wheat which he has examined.

After having devoted much time during the past several years to a careful study of the question of flour bleaching in all its relations, ${ }^{17}$ we would sum up our findings briefly as follows: The essential action of the bleaching of flour is to remove from it a small amount of yellow color which in itself is in no wise a valuable constituent in the flour from a food standpoint, and the presence of which is objectionable because it detracts from the flour in the eyes of the consumer by whom the demand for flour is created. The best results are obtained by its use only when thorough purification and cleaning are adopted, and it in no way contributes to the covering up of an unsound or damaged condition in the wheat. Any imperfections in purification or cleaning are made more apparent by the bleaching because these defects are in a manner covered by the coloring matter when it is present. Any improvement in quality brought about by removing an unusually large amount of color present in a flour which was inferior because of the presence of such excess of color certainly cannot be looked upon as in any way injuring or deceiving the consumer, as has been contended by some, for the cause which produced the inferiority now no longer exists. The purpose of the bleaching is to remove and not to conceal the inferiority. The prohibition of the bleaching of flour will curtail the use and cut down the price of durum wheat and all wheats which have an intense yellow color in spite of the fact that aside from this some of these wheats produce flour of the very highest quality. The effect of this is naturally felt more by the producer of wheat and the consumer of flour than by the miller whose prices are regulated by market values and competition. The most searching investigations have failed to show the presence in the commercially bleached flour of any substance that in the minute quantities in which it is present is in any way injurious to the bread-making qualities of the flour, or is in any way poisonous or has any toxicological or preservative action, or any action which is prejudicial to digestion or nutrition.

$$
\text { BIBLIOGR.APHY. }
$$

I. M. Frichot, French Patent 277751, 1898 .

2. Experimental work by ourselves and testimony given in infringement suit, Alsop vs. Nailor \& Gerrard, St. Louis, Mo., March, I907.

3. J. \&. S Andrews, English Patent I66I, I90I.

4. The Operative Miller, rgo4.

5. M. E. Fleurent, Igo6. Bulletin 3, serie XXXV, XXXVI, Société Chimique de Paris.

6. Harry Snyder, University of Minnesota Experiment Station, Bulletin III.

7. E. F. Ladd and R. E. Stallings, Bulletin 72, North Dakota Agricultural Experiment Station.

8. Dr. Avery, Journal of the American Chemical Society, 1907.

9. F. J. Alway, Nebraska Agricultural Experiment Station, Bulletin I02, I907; Alway and Pinckney, Amer. Chem. Journal, I9o8.

I0. Dr. Weil, Chemiker-Zeitung, Jan. 9, I909. 
II. Results of numerous careful comparisons by ourselves, made in the course of daily examinations of flours of all kinds, for commercial purposes.

12. Testimony in Flour Bleaching trial, Russel Miller Milling Co., et al., Plaintiffs vs. E. F. Ladd, Defendant in Third Judicial District Court of North Dakota, October, I908.

13. Results of numerous unpublished experiments by ourselves.

I4. E. F. Ladd, Government Agricultural Experiment Station, Special Bulletin 9, Agricultural College, N. D., December, 1908, and testimony as in reference No. I 2 .

I 5. Flour Oxidizing Co., owners of the Andrews Patents, vs. J. and R. Hutchinson, England.

I6. American Food Journal, Chicago, Sept. I5, 1907.

I7. Numerous papers and addresses by ourselves published in American Miller, Northwestern Miller, Operative Miller, Baker's Helper, Baker's Review, r904-1909.

THE COLUMBUS LABORATORIES, Chicago.

\section{THE TITANIUM ARC.}

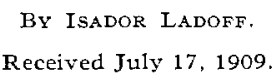

I was fortunate to be present when Dr. E. Weintraub stcceeded in striking an arc between two mercury terminals in vacuo by his ionization method at the Research Laboratory of the General Electric Co., then just called into existence by the sagacity of Mr. C. P. Steinmetz.

The mere fact that metallic vapors, even under such artificial conditions as a high vacuum, could give so much light was a revelation to me. I, of course, noticed the undesirable color of the arc and even at that time considered the mercury of very limited importance as a source of illumination. However, I realized fully the immense scientific interest of this arc. The idea occurred to me that some metals, or combinations of metals, might be found which would give satisfactory arc light illumination in the free air.

Since that time the idea of a metallic arc in the open air for lighting purposes turned into a fixed idea with me. In the spring of I902 I was occupied in eliminating from a molten bath of copper the occluded gases. The color of the copper vapors, by a very natural association of ideas, recalled to my mind the mercury arc. I then started to study the voltaic arc, with the view of advancing my scheme of a metallic source of illumination in the open space.

It is a matter of common knowledge that carbon possesses the highest point of electro-vaporization among all-non-metallic elements known to chem- istry and that carbon was therefore considered as the only material so far available or arc lighting. The connection between the point of vaporization and intensity of the arc light could be easily explained by the following familiar analogy:

Water subjected to heating in a vessel absorbs the heat supplied to it until it reaches the vaporization point. From the time this temperature is attained all the additional supply of the heat energy is consumed in the work of evaporization. It is obvious that the heating of a black body like carbon, whose vaporization point is very high, must result in the manifestation of some other form of energy expenditure than mere vaporization. This form of energy is light. The higher the vaporization point of the body heated--the more intensely luminous must be its arc. In fact, its light must increase with the temperature. This is known to be strictly true of so-called black bodies, of which carbon is the nearest approach to theory. This line of reasoning compelled me to look for some metallic compound or metal having an electrovaporization point nearest to that of carbon.

I ound that among all metals titanium possesses the highest point of vaporization, ${ }^{1}$ and that this point is the nearest to the point of vaporization of carbon.

Another consideration in favor of using titanium as a material for arc light illumination was, that among all metals it furnishes the richest spectrum as far as the number of lines is concerned. Indeed, titanium excels all non-rare metals in the nature and extent of the light-giving part of the spectrum. Thalen counted 201 lines in the red part of the spectrum out of 6,556 ; about 4,163 in the violet. Leveyng and Dewar counted between the same four new ones and Corner 25 in the ultraviolet, together 230 lines, two in the red, 17 in the orange, 32 in the yellow, 70 in the green, 35 in the blue, 45 in the indigo and 4 violet lines. I 8 Fraunhoffer lines were recognized in the photosphere of the sun; 32 of these were artificially restored by Leveyng and Dewar to their actual state.

One drawback possessed by titanium as a source of illumination is its comparatively low electric conductivity.

With this conclusion in my mind, I made a great effort to find out whether my purely theoretical considerations were corroborated by facts. I ransacked my memory and tried to get

\footnotetext{
${ }^{1}$ See Mendelejéff's tables.
} 